SHS Web of Conferences 2, 00001 (2012)

DOI: $10.1051 /$ shsconf $/ 20120200001$

(C) Owned by the authors, published by EDP Sciences, 2012

\title{
Music therapy in the psychosocial rehabilitation of people with epilepsy
}

\section{Z. Abramaviciute and V. Aleksiene}

\author{
Vilnius Pedagogical University, Lithuania \\ Social Communication Institute, Lithuania
}

\begin{abstract}
The article presents a pilot study analysing the application of music therapy in the today's psychosocial rehabilitation of people with epilepsy. The study is based on the analysis of the up-to-date application of music therapy in psychosocial rehabilitation, outcomes of epilepsy and special needs of people with this disorder. The analysis serves as a basis for making the assumption that music therapy is an effective measure addressing psychosocial issues of patients suffering from epilepsy. To achieve the objective set, an on-line survey method was used. A questionnaire was sent to the European Confederation of Music Therapy, the International Fellowship in Music Therapy for Neuro-disability, and several members of the World Federation of Music Therapy. It is difficult to formulate final conclusions about the today's role of music therapy in the psychosocial rehabilitation of people suffering from epilepsy on the basis of this study as the sample is not representative. The analysis of literature and the results of the survey prove the issue of the role of music therapy in the psychosocial rehabilitation of epileptic people to be complex. The service of music therapy should be integrated into health promotion programmes focused on meeting special needs of people with epilepsy and implemented by an interdisciplinary team. Music therapy is applied specifically and diversely subject to symptoms of the disorder and the therapeutic objectives set. Crystallising the specificity of the application of music therapy in this context requires further research.
\end{abstract}

Key words: music therapy, epilepsy, psychosocial rehabilitation

More thorough scientific research of epilepsy started in the $19^{\text {th }}$ century, when the establishment of specialised care centres opened up the opportunity to perform clinical observations (Haynes et al., 1992). These observations helped examine the disorder in terms of aetiology, pathology, diagnosis, prognosis and treatment, noting from time to time its effects on personality changes or cognitive disorders. ${ }^{1}$ Today's epilepsy research activities are much wider and diverse. Experimental and clinical epileptology includes basic and clinical interdisciplinary research ${ }^{2}$ examining clinical (Malikova et al., 2011; de Araújo Filho et al., 2011), neurological (Sherman et al., 2011; Truccolo et al., 2011), biological (Pack et al., 2011), genetic (Scharer et al., 2010; Wierschke et al., 2010), psychiatric (Sankar et al., 2010; Redden et al., 2011), therapeutic and treatment related (Elliot et al., 2011; Macrodimitris et al., 2011;

This is an Open Access article distributed under the terms of the Creative Commons Attribution License 2.0, which permits unrestricted use, distribution, and reproduction in any medium, provided the original work is properly cited.

1 The most notable researchers of that period include: neurologist, professor of anatomical pathology Jean M. Charcot (18251893); psychiatrist, medical historian Louis F. Calmeil (1798-1895); the notorious physiologist of the Victorian era John R Reynolds (1828-1896); predecessors of the English neurology William Gowers (1845-1915) and John H. Jackson (1835-1911). Each of them significantly contributed to the identification of the real nature and outcomes of the disorder. For instance, L. F. Calmeil was the first to define absence, thus separating epilepsy from hysteria, and status epilepticus described as uncontrollable sequence of seizures which often results in death. The leading role in epilepsy research at that time was played by J. H. Jackson. He presented the concept of epilepsy as local electric discharge in a nervous tissue, identified the physiological location of seizure, and thoroughly described the spread of seizure. According to him, the focus of seizure, the nature of disease and the cause of pathology may be determined by observing the nature of convulsions, their shifting in time and the post-seizure condition of a person (Haynes et al., 1992).

${ }^{2}$ Research activities are based on the knowledge on neurology, neurosurgery, neuroendocrinology, neurophysiology, neuropharmacology, neurogenetics, neuropsychology, brain imaging, neuropsychiatrics, molecular neurobiology, clinical chemistry, paediatric neurology, and neurotoxicology. The most important sources publishing epilepsy research are journals Epilepsy Research, Seizure, Epilepsia, Epilepsy\&Behavior, the Cochrane Library (Epilepsy Group, www.epilepsy.cohrane.org). 


\section{SHS Web of Conferences}

Ramaratnam et al., 2008; Schmidt, 2011) aspects of epilepsy. Various researches of the quality of life (Westerhuis et al., 2011) are carried out in the context of psychological sciences. Social epileptology scrutinises social and psychosocial sides of the disorder (Pinikahana et al., 2010).

Up to now, scholars have paid rather little attention to research of the application of music therapy in the psychosocial rehabilitation of people with epilepsy, contrary to, for example, dementia or other neurodegenerative diseases, in case of which the practice of music therapy has been examined rather thoroughly (Baumann et al., 2007; Aldridge (ed.), 2005; Trias (ed.), 2001). In the context of epilepsy, research analysing exceptional neurological/psycho neurological characteristics of music and epilepsy should be mentioned. Making insights into their inter-parallels aims at finding the impact of listening to music on the mechanisms of epileptogenesis and psycho-physiological symptoms of the disorder (Hughes, 2001, 2002; Lahiri et al., 2007; Sidorenko, 2000; Kaplan, 2003; Turner, 2004). ${ }^{3}$

Issues related to the application of music therapy when addressing psychological or psychosocial issues of patients are discussed only in anecdotal cases (e.g. Torre, 2001). ${ }^{4}$

The article presents a pilot study analysing the application of music therapy in the healthcare of people with epilepsy today. The initial insights are based on the examples of the research or anecdotal cases presented. Such insights may be expanded by the analysis of outcomes of epilepsy and related healthcare needs of people suffering from this disorder.

"It is imperative to recognize that epilepsy consists of more than seizures for the affected individual and immediate effects on his or her family. Epilepsy leads to multiple interacting of medical, psychological, economic and social repercussions, all of which need to be considered in order to understand fully the impact of this condition. Fear, misunderstanding and the resulting social stigma and discrimination surrounding epilepsy often force people with this disorder "into the shadows". (Anonymous, 2005). Therefore, the emphasis is on the importance of patients' complex healthcare, where next to pharmaceutical and non-pharmaceutical treatment an important role is played by rehabilitation $^{5} /$ social rehabilitation $^{6}$ meeting patients' psychosocial needs (Anonymous, 2005).

The starting point of the study discussed in this article is the classification of indications of music therapy in the neurological rehabilitation presented by a group of German music therapists

\footnotetext{
${ }^{3}$ Most of the studies try to prove the hypothesis that listening to music may help normalise the brain activity, thereby reducing the intensity and frequency of seizures. Scientists experiment with Mozart's music and with the so-called Medical Resonance Therapy - Music (MRT-Music). In the first case, the positive effect is explained by the fact revealed during the research that the structure of Mozart's music conform to the in-depth structure of the cerebrum cortex, therefore listening to this music normalises the activity of neurons (Hughes, 2001, 2002; Lahiri et al., 2007). The other case aims at grounding the effectiveness of MRT-Music as the treatment of psycho-physiological epilepsy, focusing on the frequency and complexity of seizures, the subjective condition of the patient, symptoms between paroxysms, and dynamics and parameters of functional asymmetry of the individual brain (Sidorenko, 2000). The results of the latter research showed that the frequency and complexity of paroxysms positively changed in $80 \%$ of the cases: the frequency of seizures dropped down by $75 \%$. It also reduced the level of amnesia during the seizure and polymorphism. In $90 \%$ of the cases, changes in the subjective condition were positive: patients felt better, they were calmer and in a better mood, as well as had fewer mood swings. Patients proved to be less irritated, bitter, strained and restless. The assessment of patients using the Minnesota Multiphasic Personality Inventory (MMPI) revealed positive trends of the clinical picture between seizures, in particular aspects that characterise psychological weakness and paranoia, e.g. such conditions as hypochondria, aggression and depression. The percentage share of such changes in the control group was much smaller. The remaining studies analyse musicogenic epilepsy (Kaplan, 2003).

4 Anecdotal cases on the effectiveness of music in treating epilepsy are described in sources of different periods. For example, Ancient Greek papers mention a thinker Ismenias who claimed that epilepsy was effectively treated by music of aulos (an oboelike wooden instrument with a tongue) (quoted from West, 2000); in his work The Influence of Music on Health and Life (1875) a French doctor Hector Chomet describes a case where listening to music helped prevent a seizure (quoted from Licht, 2007). The importance of music in the treatment of epilepsy in different periods is proved by the scientific study of W. F. Kümmel Musik und Medizin: Ihre Wechselbezienhugen in Theorie und Praxis von 800 bis 1800 (Freiburg, 1977). In the work telling the history of music therapy, the author arranged its chapters by diseases subject to music therapy rather than by periods. Epilepsy is mentioned alongside melancholy, fever, insomnia, plaque, tuberculosis, apoplectic stroke and pain (Horden (ed.), 2000).

5 In case of epilepsy, rehabilitation is defined as care of people suffering from this disorder in order to help them achieve the optimal level of functioning (Anonymous, 2005).

${ }^{6}$ In case of epilepsy, social rehabilitation is defined as services being a part of the programme focused on the improvement of social abilities, facilitation of integration into work-related life, and development of skills of independent life (Anonymous, 2005).
} 


\section{Int. Conf. SOCIETY. HEALTH. WELFARE; Congr. of Rehabilitation Doctors of Latvia}

(Baumann et al., 2007). The main symptoms affecting the need for rehabilitation in case of epilepsy are the inability to deal with illness, social isolation and loss of control. The first symptom is elaborated with regard to the International Classification of Diseases (ICD-10). It includes depressive episode (F32), behavioural syndromes associated with psychological disturbances and physical factors (F59), disturbances of smell and taste (R43), symptoms and signs involving emotional state (R45), and problems related to social environment (Z60).

The source above groups indications to the application of music therapy in the neurological rehabilitation subject to the nature of disturbances or problems resulting from a certain neurological condition. As for the symptoms of epilepsy distinguished, three groups are relevant, namely drive disorders resulting from depression, e.g. reduced initiative/drive, outcomes of psychosocial side effects, e.g. stigma, fear, and social isolation, and defective states of stress, e.g. mental tension.

The review of the outcomes of epilepsy and indications to the practice of music therapy in the rehabilitation of patients shows that music therapy may be an effective measure in addressing their psychosocial problems. This thesis also is based on the scientific studies (Baumann et al., 2007) carried out on the application of music therapy in the psychosocial rehabilitation.

\section{Materials and methods}

To find out the role of music therapy in today's healthcare of people with epilepsy, an on-line survey method was applied. A questionnaire was sent to the European Confederation of Music Therapy, the International Fellowship in Music Therapy for Neuro-disability, and several members of the World Federation of Music Therapy. ${ }^{7}$

The questionnaire consisted of eight questions on structural aspects and aspects of the music therapy content. In the first case, the attention was paid to the form of music therapist's work with patients suffering from epilepsy (private work - work in an institution; individual practice - group practice; work in an interdisciplinary team). It was requested to describe institutions by the type of the services they provide and the work in an interdisciplinary team by specifying qualifications of its members. Questions on the content of music therapy were focused on the symptoms relevant to the practice of music therapy, music therapy methods and outcomes.

\section{Results}

The questionnaire was sent to 26 respondents from different countries. 11 replies were received in total: one from Iceland, Serbia, the United Kingdom, Australia, and France, and two from Switzerland, Estonia and Germany.

The data received show that the majority of music therapists have worked/work with people suffering from epilepsy in institutions, not privately (10 and 5, respectively). The said institutions, such as a hospital, a rehabilitation centre and a special needs school, mostly provide healthcare or educational services (6 replies each). One respondent indicated a social-cultural institution. 7 out of 11 respondents indicated as having experience of interdisciplinary work. The composition of a team was different in each case, subject to the type of institution. It usually contained such specialists as neurologists, psychologists, psychiatrists and psychotherapists, in rare cases - social workers, special pedagogues, pedagogues, class assistants, rehabilitation specialists, physiotherapists, ergotherapists, speech therapists and occupational therapists. 9 respondents indicated as having experience in individual work and 7 respondents - in group work with their patients.

\footnotetext{
7 At first, the target group was formed, i.e. music therapists experienced in working with people suffering from epilepsy were selected. If consented to further cooperation, they were sent a questionnaire presented in this article.
} 


\section{SHS Web of Conferences}

Table 1. Indications to the application of music therapy in healthcare of people with epilepsy The left column of the table indicates the frequency of answers, which is expressed in the number of the answers received.

\begin{tabular}{|c|c|c|c|c|}
\hline Rate & Drive disorders & Psychosocial side effects & $\begin{array}{l}\text { Defective } \\
\text { states of } \\
\text { stress }\end{array}$ & Other \\
\hline 7. & & $\begin{array}{l}\text { Impairment of self-perception and perception of } \\
\text { other people, lack of ideas and imagination, } \\
\text { apathy, social withdrawal }\end{array}$ & & \\
\hline 6. & $\begin{array}{l}\text { Reduced drive, } \\
\text { reduced initiative }\end{array}$ & Self-esteem problem & & \\
\hline 5. & $\begin{array}{l}\text { Reduced emotional } \\
\text { expression, limited } \\
\text { ability to express } \\
\text { changes in emotion }\end{array}$ & $\begin{array}{l}\text { Fear, sadness, withdrawal, attitude of non- } \\
\text { compliance, behavioural stereotypes }\end{array}$ & $\begin{array}{l}\text { Mental } \\
\text { tension }\end{array}$ & \\
\hline 4. & & $\begin{array}{l}\text { Inability to deal with illness, emotional instability, } \\
\text { aggression, destructive behaviour, self- } \\
\text { consciousness, timidity, insecurity, shyness, } \\
\text { limited (verbal) communication between } \\
\text { patient and relative }\end{array}$ & & \\
\hline 3. & & $\begin{array}{l}\text { Depressive episodes, limited ability to express } \\
\text { changes in emotion }\end{array}$ & & \\
\hline 2. & & $\begin{array}{l}\text { Identity disorder, inability to keep a distance, lack } \\
\text { of inhibition }\end{array}$ & & $\begin{array}{l}\text { Seizure } \\
\text { activity }\end{array}$ \\
\hline 1. & $\begin{array}{l}\text { Fluctuating awareness, } \\
\text { difficulty in moving }\end{array}$ & Exaggerated conformity & & \\
\hline
\end{tabular}

Table 2. Methods of music therapy.

\begin{tabular}{|l|l|}
\hline Active MT & Passive MT \\
\hline Playing instruments/playing rhythmic instruments & Listening to recorded/live music \\
\hline Singing/singing with instrumental accompaniment & Writing in accordance to instrumental music \\
\hline Instrumental improvisation (expression, exploration) & \\
\hline Sound exchange in dual relationships $\rightarrow$ verbalisation & \\
\hline
\end{tabular}

Answers to the questions on the symptoms relevant to the application of music therapy in the rehabilitation of people suffering from epilepsy ${ }^{8}$ disclose that the music therapists surveyed usually face different psychosocial problems such as social isolation, apathy, inadequate self-perception and perception of other people, etc. Drive disorders, e.g. reduced initiative/reduced drive, as well as defective states of stress, e.g. mental tension, are also highly significant (see Table 1). Important information for interpretation of the results is provided by the comments of respondents. Four of the surveyed noted that their clients suffered from multiple health disorders.

In the light of the answers to the open question on methods of music therapy, it may be stated that a range of the methods used include active and passive music therapy (see Table 2). Some of the respondents named methods in connection with different music therapy models, e.g. one of them

\footnotetext{
${ }^{8}$ A list of symptoms provided to the respondents was made on the basis of the classification described in the introduction of the article. It is important to note that it implies neurotic problems of a general nature rather than epilepsy-specific disturbances. Answering to this question the respondents could leave their comment.
} 
Int. Conf. SOCIETY. HEALTH. WELFARE; Congr. of Rehabilitation Doctors of Latvia

Table 3. Music therapy outcomes.

\begin{tabular}{|l|l|}
\hline Symptoms & Outcomes \\
\hline Drive disorders & Increased initiative, motivation to act \\
\hline Psychosocial side effects & $\begin{array}{l}\text { Intrapersonal level: } \\
\text { Increased self-esteem, improvement of self-perception / self-awareness, } \\
\text { emotional release, higher amount of positive emotions / feelings, increased } \\
\text { inspiration to create, development of musical skills, imagination } \\
\text { improvement, inner locus of control. } \\
\text { Interpersonal level: } \\
\text { Positive changes in communication, experiences of group cohesion / } \\
\text { feelings of belonging, solidarity, cooperation with authority. }\end{array}$ \\
\hline Defective states of stress & \begin{tabular}{l} 
Induced relaxation and / or sleep \\
\hline
\end{tabular} \\
\hline
\end{tabular}

indicated the integral mode, and another claimed using various methods: developmental, creative, psychodynamic, and behavioural.

Open answers regarding the overall impact of music therapy were analysed with regard to the provided list of possible symptoms. In case of drive disorders, the respondents distinguished their client's increased motivation and initiative; in case of defective states of stress - induced relaxation and/or sleep. The music therapists also indicated better psychosocial functioning of patients both at intrapersonal and interpersonal levels (see Table 3).

\section{Discussion}

The results of the study related to the structural peculiarities of the application of music therapy in the psychosocial rehabilitation of people with epilepsy reveal the general trends of health promotion in this area. The results of studies conducted by the World's Health Organisation (WHO) reveal that healthcare establishments mentioned by the respondents the most are responsible not only for pharmaceutical treatment, but also play an important role in identifying the special needs of patients and organising rehabilitation and special education services accordingly (Anonymous, 2005). Special services in educational establishments are of particular relevance as a large part of children face different social problems at school, e.g. stigma and social isolation (Anonymous, 2005). Some of epileptic people suffer a number of disturbances associated with this disorder; therefore, special education establishments mentioned by the respondents play a significant part in health promotion.

The principal factor positively influencing the quality and effectiveness of healthcare in case of epilepsy is interdisciplinary cooperation (Anonymous, 2005). The latter one was distinguished by a larger part of the respondents as a form of work with patients. According to the data published by the WHO, the medical professionals named by the respondents, e.g. neurologists and psychiatrists, play the leading role in the today's healthcare of people with epilepsy. Alongside them, other healthcare professionals, e.g. psychologists, social workers and neurology nurses, were also indicated by the music therapists surveyed (Anonymous, 2005).

The results of the study reveal that the respondents working with people suffering from epilepsy have faced a wide range of symptoms in the professional practice. The opportunities to apply the service itself are also rather different. It is proved by the answers of the music therapists on the music therapy methods in use. However, it should be noted to the respondents' comments above (in the section of results) stating that their patients face multiple health disorders. In such a case, a specific symptom may result not from epilepsy, but from other health disorders (e.g. as one of the respondents noted, the symptom "inadequate self-perception and perception of other people" is apparent, but the patient is also autistic and has a brain tumour). Furthermore, one of the respondents commented that despite the fact that the patient had epilepsy, the disorder itself did not meet the focus of the therapeutic process in 


\section{SHS Web of Conferences}

most cases. Hence, the answers on the role of music therapy in the promotion of peoples' with epilepsy health are associated with the aetiology of the disorder and multiplicity of outcomes that are especially evident in the psychosocial context. Treatment of such people is complex. Music therapy is applied both in treatment and psychosocial rehabilitation programmes, but its effectiveness requires more thorough research.

\section{Conclusions}

1. It is difficult to formulate final conclusions about the today's role of music therapy in the psychosocial rehabilitation of people suffering from epilepsy on the basis of this study as the sample is not representative. However, considering the fact that the issues of a similar nature have not been thoroughly examined, the results received are important for the more exhaustive research in future.

2. The analysis of literature and the results of the survey prove the issue of the role of music therapy in the psychosocial rehabilitation of epileptic people to be complex. The service of music therapy should be integrated into health promotion programmes focused on meeting special needs of people with epilepsy and implemented by an interdisciplinary team. Music therapy is applied specifically and diversely subject to symptoms of the disorder and the therapeutic objectives set.

3. The effectiveness of music therapy in the psychosocial rehabilitation (without singling out epilepsy) is confirmed by the scientific experience gathered up to date. Therefore, it may be claimed that integration of music therapy services into the health promotion of epileptic patients, to be more precise, into the solution of psychosocial problems of people suffering from this disorder, will have a positive effect on the health promotion process itself. Crystallising the specificity of the application of music therapy in this context requires further research.

\section{References}

[1] Aldridge, D. (Ed.) (2005) Music Therapy and Neurological Rehabilitation. - London and Philadelphia: Jessica Kingsley Publishers, p. 302.

[2] Anonymous (2005) Atlas: Epilepsy Care in the World. Programme for Neurological Diseases and Neuroscience. Department of Mental Health and Substance Abuse. - Geneva: World Health Organization.

[3] Baumann, M., Hinkelmann, A., Jochheim, M., Mainka, S., Starub, S., Unterharnscheidt, M. (2007) Indications for Music Therapy in Neurological Rehabilitation. - Berlin: Deutsche Gesellschaft für Musiktherapie.

[4] de Araújo Filho, G.M., da Silva, J.M., Mazetto, L., Marchetti, R.L., Yacubian, E.M. (2011). Psychoses of epilepsy: A study comparing the clinical features of patients with focal versus generalized epilepsies. Epilepsy \& Behavior. - PMID: 21450532.

[5] Elliot, R.E., Morsi, A., Tanweer, O., Grobelny, B., Geller, E., Carlson, C., Devinsky, O., Doyle, W.K. Efficacy of vagus nerve stimulation over time : Review of 65 consecutive patients with treatment-resistant epilepsy treated with VNS >10years. Epilepsy \& Behavior, 20(3), 478-483. PMID: 21296622.

[6] Haynes, S.D., Bennett, T.L. (1992) Historical perspective and overview. In Bennet, Th.L. (ed.), The Neuropsychology of Epilespy (p. 3-17). - New York and London: Plenum Press.

[7] Hermann, B.P., Whitman, S., Anton M. (1992) A Multietiological Model of Psychological ans Social Dysfunction in Epilepsy. In Bennett, Th.L. (ed.), The Neuropsychology of Epilepsy (p. 39-57). - New York and London: Plenum Press.

[8] Horden, P. (2000) Musical Solutions: Past and Present in Music Therapy. In Horden, P. (ed.). Music as Medicine. The History of Music Therapy since Antiquity (p. 4-43). - Aldershot, Brookfield USA, Singapore, Sydney: Ashgate.

[9] Hughes, J.R. (2001) The Mozart Effect. Epilepsy \& Behavior, 2 (5), p. 396-417. 
Int. Conf. SOCIETY. HEALTH. WELFARE; Congr. of Rehabilitation Doctors of Latvia

[10] Hughes, J.R. (2002) The Mozart Effect: Additional Data. Epilepsy \& Behavior, 3 (2), p. $182-84$.

[11] Kaplan, P.W. (2003) Musicogenic epilepsy and epileptic music: a seizure‘s song. Epilepsy \& Behavior, 4 (5), p. 464-473.

[12] Lahiri, N., Duncan, J.S. (2007) The Mozart effect: Encore. Epilepsy \& Behavior, 11 (1), p. 52153.

[13] Licht, S. (2007) History of Music in Medicine. In Licht, S. Music in Medicine (p. 1-15). Vintage Dog Books.

[14] Macrodimitris, S., Wershler, J., Hatfield, M., Hamilton, K., Backs-Dermott, B., Mothersill, K., Baxter, C., Wiebe, S. (2011) Group cognitive-behavioral therapy for patients with epilepsy and comorbid depression and anxiety. Epilepsy \& Behavior, 20 (1), p. 83-88.

[15] Malikova, H., Liscak, R., Vojtech, Z., Prochazka, T., Vymazal, J., Vladyka, V., Druga, R. (2011) Stereotactic radiofrequency amygdalohippocamecptomy: Does reduction of entorhinal and perirhinal corticles influence good clinical seizure outcome? Epilepsia, doi: 10.111/j.15281167.2011.03048x.

[16] Pack, A.M., Reddy, D.S., Duncan, S., Hrezog, A. (2011) Neurendocrinological aspects of epilepsy: important issues and trends in future research. Epilepsy \& Behavior, doi: 10.1016/j.yebeh.2011.02.009.

[17] Pinikahana, J., Walker, Ch., (eds.) (2010) Social Epileptology: Understanding Social Aspects of Epilepsy. - New York: Nova Science Publishers, Inc, 288 p.

[18] Ramaratnam, S., Baker, G.A., Goldstein, L.H. (2008) Psychological treatments for epilepsy. Cochrane Database of Systematic Reviews, 3, Art. No: CD002029, DOI: 10.1002/14651858.

[19] Redden, L., Pritchet, Y., Robieson, W., Kovacs, X., Garofalo, M., Tracy, K., Saltareli, M. (2011) Suicidality and divalproex sodium: analysis of controlled studies in multiple indications. Annals of General Psychiatry, 10(1):1, doi:10.1186/1744-859X-10-1.

[20] Sankar, R., Mazarati, A. (2010) Neurobiology of Depression as a Comorbidity of Epilepsy. Epilepsia, 51(s5), 81. PMID: 21415938.

[21] Scharer, G., Brocker, C., Vasiliou, V., Creadon-Swindell, G., Gallagher, R.C., Spector, E., Van Hove, J.L. (2010) The genotypic and phenotypic spectrum of pyridoxine-dependant epilepsy due to mutations in ALDH7A1. Journal of Inherited Metabolic Disease. 33(5), p. 571-581.

[22] Schmidt, D. (2011) Efficacy of new antiepileptic drugs. Epilepsy Currents, 11(1), 9-11. PMID: 21461260.

[23] Sherman, D., Zhang, N., Garg, S., Thakor, N.V., Mirski, M.A., White, M.A., Hinich, M.J. (2011) Detection of nonlinear interactions of EEG alpha waves in the brain by a new coherence measure and its application to epilepsy and anti-epileptic drug therapy. International Journal of Neural Systems, 21(2), p. 115-126.

[24] Sidorenko, V.N. (2000) Effects of the medical resonance therapy music in the complex treatment of epileptic patiens. Integrative Psychological and Behavioral Science, 35 (3), p. 212-217.

[25] Torre, L. (2001) Music therapy with a child suffering from severe epilepsy. www.musicaterapia.it/rivista/giu04/mt5.htm.

[26] Trias, G. (ed.) (2003) Music Therapy and Art Therapy in Neurodegenerative Diseases. Barcelona: Fundació "la Caixa", p. 119.

[27] Truccolo, W., Donoghue, J.A., Hochberg, L.R., Eskandar, E.N., Madsen, J.R., Anderson, W.S., Brown, E.N., Halgren, E., Cash, S.S. (2011) Single-neuron dynamics in human focal epilepsy. Nature Neuroscience, DOI: 10.1038/nn.2782.

[28] Turner, R.P. (2004) The acute effect of music on interictal epileptiform discharges. Epilepsy \& Behavior, 5 (5), p. 662-668.

[29] Viteri, C., Codina, M., Cobaleda, S., Lahuerta, J., Barriga, J., Morales, M.D. (2010) Quality of life and treatment satisfaction in Spanish epilepsy patients on monotherapy with lamotrigine or valproic acid. Seizure, 19(7), 432-438. PMID: 20663691. 


\section{SHS Web of Conferences}

[30] West, M. (2000). Music Therapy in Antiquity. In Horden, P. (ed.). Music as Medicine. The History of Music Therapy since Antiquity (p. 51-69). Aldershot, Brookfield USA, Singapore, Sydney: Ashgate.

[31] Westerhuis, W., Zijlmans, M., Fischer, K., van Andel, J., Leijten, F.S. (2011) Coping style and quality of life in patients with epilepsy: a cross-sectional study. Journal of Neurology, 258(1), 37-43. PMID:20658245.

[32] Wierschke, S., Gigout, S., Horn, P., Lehmann, T.N., Dehnicke, C., Bräuer, A.U., Deisz, R.A. (2010) Evaluating reference genes to normalize gene expression in human epileptogenic brain tissues. Biochemical and Biophysical Research Communications, 403(3-4), p. 385-390. 